Admissions to Universities and Colleges of Advanced Technology

Is written answers in the House of Commons on February 18, the Secretary of State for Education and Science, Mr. A. Crosland, stated that about 19,275 students in science and technology were admitted to universities and colleges of advanced technoiogy in October 1964, or 1,375 more than in October 1963, but about 2,000 fewer than had been planned. Recurrent Government grants to universities and colleges during the financial years 1961-62 to 1964-65 were: $1961-62$, $£ 57.9$ million; 1962 63 , 556.8 million; $1963-64, £ 69.4$ million; and $1964-65$, $£ 86$ million. The corresponding capital grants were: $£ 26.2$ million, $£ 32.8$ million; $£ 40.7$ million, and $£ 57.5$ million, respectively.

\section{Underground Transmission Lines}

In reply to questions in the House of Commons on February 16 regarding underground transmission lines, the Parliamentary Secretary to the Ministry of Power, Mr. J. Morris, said that out of a total expenditure on research and development of about $£ 7$ million a year by the Central Electricity Generating Board and the Area Boards, roughly $£ 1$ million was spent on transmission and distribution, of which between 10 and 20 per cent was spent on placing cables underground. Much research was carried out by manufacturers and supported by the Boards through their purchases of cables. The Central Electricity Generating Board had placed, or was placing, contracts of about $£ 21$ million for $275-\mathrm{kV}$ and $400-\mathrm{kV}$ cables of a pioneering type, with an exceptionally large cross-section and provision of water-cooling. These contracts reflected much indirect support for the cable manufacturers' research and development. The Central Electricity Generating Board was giving much thought to the possibility of underground cables, but for a $400-\mathrm{kV}$ line the cost was about $f 1$ million a mile-between 18 and 20 times that of taking it above ground. At March $31,1964,7.6$ per cent of circuit miles of the Central Generating Board were laid underground and 40.9 per cent of those of the Area Boards of more than $650 \mathrm{~V}$. In 1962-63 the Central Electricity Board incurred 47.5 por cent of its capital expenditure on transmission cable or underground cables, and $42 \cdot 6$ per cent in 1963-64; for the Area Boards the corresponding figures are 82.2 per cent and 83.6 per cent.

\section{Water Barrages}

IN reply to questions in the House of Commons on February 16 about the supply of power from water barrages, the Parliamentary Secretary to the Ministry of Power, Mr. J. Morris, said that while the Central Electricity Generating Board had noted the work being done by Mr. E. M. Wilson in the Department of Civil Engineering at the University of Sheffield on a barrage for the Solway Firth and the plan for a barrage across Morecambe Bay, it had estimated that in the most promising schemes so far proposed in Britain, the cost of generating electricity by tidal barrage would not be competitive. In reply to further questions on February 18, the Parliamentary Under-Secretary of State for Economic Affairs, Mr. W. Rodgers, said that proposals for barrage schemes in the Solway Firth, Morecambe Bay and the Dee Estuary were already being examined in the context of regional economic planning and it was hoped to make a statement shortly. It was recognized that this was not just a matter of the generation of electricity but that roads, the conservation of water and many other factors had to be taken into account. It was most important to consider all these schemes together and not the merit of any one of them in isolation.

\section{Carnegie Institution of Washington}

THE Report of the President of the Carnegie Institution of Washington for 1963-64 gives new information concern- ing the most distant visible objects in the Universe; new estimates of the age of the Earth and the size of the Earth's core; progress in the understanding of how organs of the body are formed and how living colls differentiate (Pp. $73+\mathrm{xi}+5$ plates. Reprinted from Carnegie Institution of Washington Year Book 63 for the year 1963-64. Washington, D.C.: Carnegie Institution of Washington, 1964). The age of the Earth is now given as 4.7 billion years, and the examination of samples of material from St. Paul's Rocks, a group of islands located on the midAtlantic ridge, gave an age of 4.5 billion years; this would make them the oldest known rocks on the surface of the Earth.

\section{Association for Education in France}

French Science News (No. 2; April-June 1964) records the foundation of the Association for Education in France, to promote co-operation between university and industry within the scope of the science faculties of the Universities of Paris, Grenoble and Nancy. The board of directors consists of an equal number of university professors and industrial representatives. Premises are under construction at the Orsay Faculty. The first objective will be to train engineers to a high degree of scientific culture; for the two years following their qualification they will be given special tuition which will include the new branches of science best adapted to their future industrial career. The second aim is to organize full-time refresher courses, lasting from a week to a fortnight, for practising engineers; these courses are to provide either a general or specialized training.

\section{L'Association des Physiologistes}

L'Association des Physiologistes held the first of its biannual meetings of 1965 at Marseilles during February 10-13. About 200 members attended; the four-day meeting was divided into two days of demonstrations followed by two days of short papers and discussions. More formal lectures will be included in the programme for the principal meeting of the Association, to be held at the end of June at Louvain, Belgium. The Association was founded in 1926 and owed its inception particularly to Profs. André Mayer and Emile Terroine of Strasbourg. The early membership was drawn from France, Belgium and Switzerland. The words "de la langue Française" were added to the Association's title soon after its formation, but with the extension of its membership in recent years to countries where French is not the native tongue, the original title has been resumed. The proceedings of each meeting are recorded in the Journal de Physiologie, published biannually in Paris.

\section{Nuclear Structural Engineering}

AN apparently widespread feeling of dissatisfaction among engineers that existing nuclear engineering literature does not yet provide an appropriate outlet for material in the field of nuclear structural engineering has led to the establishment of the new international journal Nuclear Structural Engineering. It is devoted to the civil, mechanical and chemical structural engineering problems of nuclear power plants, of radiation facilities and of radioactive waste. Particular aspects include heat transfer, stress analysis, the design, fabrication and testing of roactor components and materials, reactor layout and safety considerations, and radiation protection. The editor, Dr. T. A. Jaeger, is a lecturer in nuclear structural engineering at the Technical University, Berlin, and he is assisted by 26 section editors from sixteen countries including Japan and the U.S.S.R., but not China. The journal is to appear bi-monthly. The first number (January 1965) contains 12 articles, two notes and two book reviews, together with bibliographical notes concorning the section editors, and consists of 139 pages. Each volume, costing $£ 9$, will have about 500 pages. It is published in Amsterdam by the North-Holland 